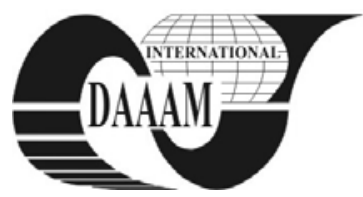

Annals of DAAAM for 2011 \& Proceedings of the 22nd International DAAAM Symposium, Volume 22, No. 1, ISSN 1726-9679 ISBN 978-3-901509-83-4, Editor B. Katalinic, Published by DAAAM International, Vienna, Austria, EU, 2011 Make Harmony between Technology and Nature, and Your Mind will Fly Free as a Bird Annals \& Proceedings of DAAAM International 2011

\title{
NUMERICAL CREEP BUCKLING ANALYSIS OF THIN-WALLED STEEL FRAME
}

\author{
MERDANOVIC, E[din]; LANC, D[omagoj] \& TURKALJ, G[oran]
}

\begin{abstract}
Paper presents creep buckling numerical modeling of steel beam-type structure. Finite element simulation is applied using four nodded Kirchoff-Love theory based shell elements. For test example, one-storey one-bay space frame, critical buckling times are evaluated varying load levels, temperature as well as chemical composition of carbon steel.

Key words: beam, buckling, creep, frame, stability
\end{abstract}

\section{INTRODUCTION}

In the field of structural engineering beams and frames constitute a very important class of load-carrying components, where they are applied both in their stand-alone forms and as stiffeners for some plate or shell assemblages. Because such structures, especially those of thin-walled cross-sections, could display very complex structural behavior which comprises both geometric and material inelasticity, has been a major activity of many structural engineering researchers in the recent years.

Columns under sustained loads are generally unstable in the regime of creep. That means that loss of stability may occur during a period of exploitation of structure even for loads lower than critical buckling load. Due to that reason stability is characterized by critical buckling time defined as load duration for which buckling deflections become infinitive (Lanc et al., 2008).

Shell elements are especially useful when the behavior of large structures is of interest. The flat shell elements are the simplest ones due to their low computational cost, so such elements are very popular. Contrary to Mindlin-Reissner type, Kirchoff-Love type based shell elements neglect transverse shear deformation (Nguyen-Thanh et al., 2008).

In this paper a beam finite element model is used to evaluate the critical buckling loads of the frame as eigenvalues. Afterwards, for geometrically and materially nonlinear creep buckling analysis shell finite element model is used.

\section{CREEP MODELING}

Creep material behavior can be modeled according to equation (Lanc et al., 2006):

$$
{ }^{2} \varepsilon_{i j}{ }^{\prime}={ }^{2} \varepsilon_{i j}{ }^{\prime}-{ }^{1} \varepsilon_{i j}{ }^{c}
$$

while ${ }^{2} S_{i j}$ is deviatoric stress tensor in configuration $C_{2}$ and $\varepsilon_{i j}{ }^{c}$ denotes creep deformation tensor.

Creep deformation increment can be calculated as:

where factor

$$
\Delta \varepsilon_{i j}{ }^{c}={ }^{1} k^{1} S_{i j}
$$

$$
{ }^{1} k=1.5\left({ }^{1} \overline{\dot{\varepsilon}}^{c} /{ }^{1} \bar{\sigma}\right) \Delta t
$$

with $\overline{\dot{\varepsilon}}^{c}$ and $\bar{\sigma}$ as effective creep strain rate and effective stress. In the case of creep configurations $C_{1}$ and $C_{2}$ are real time configurations, and time increment $\Delta t$ represents the real time passed during the element movement from configuration $C_{1}$ to configuration $C_{2}$. Effective creep strain rate $\overline{\dot{\varepsilon}}^{c}$ from equation (3) can be obtained according to Norton power creep law as:

$$
\overline{\dot{\varepsilon}}^{c}=K \bar{\sigma}^{n}
$$

where $K$ and $n$ are Norton material constants.

\section{EXAMPLES}

Figure 1 shows a one-storey one-bay space frame loaded by four vertical forces, each of intensity $F$. All the frame members are made of W10 $\times 49$ section. The material moduli is $E=210$ GPa. The length of each beam is $l=3900 \mathrm{~mm}$ and of each column is $H=3773 \mathrm{~mm}$. Three different finite element models are made. A beam finite element model with 80 elements and a shell finite element model with 5984 elements are made in FEMAP. One beam model with 8 elements is made in THINWALL. To obtain critical buckling load, eigenvalue analyses are performed by beam and shell FEMAP as well as THINWALL computer solver. The elastic buckling loads obtained from the above mentioned models are listed in Table 1 . The first two buckling modes are sway modes in $X$ and $Z$ axis directions and the third one is twist mode (Fig. 1).

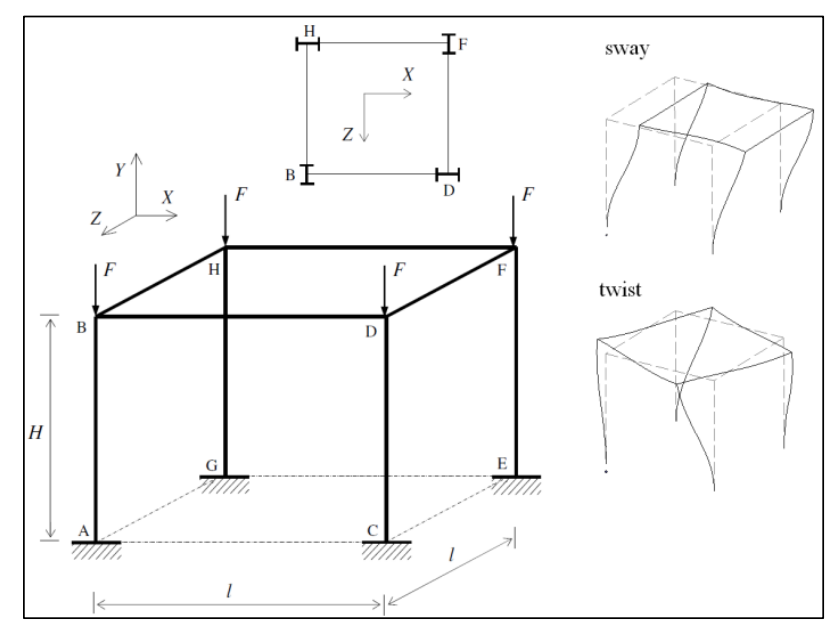

Fig. 1. One-storey one-bay space frame

\begin{tabular}{|l|c|c|}
\hline FE model & No. of elements & Buckling load (MN) \\
\hline FEMAP beam & 80 & 8.1 \\
\hline FEMAP shell & 5984 & 8.3 \\
\hline THINWALL & 8 & 8.2 \\
\hline
\end{tabular}

Tab. 1. Buckling loads for different finite element models

For a creep buckling analysis, the frame is loaded with three different constant forces: $4 \mathrm{MN}$ (it is about $0.5 F_{\mathrm{cr}}$ ), 5.75 $\mathrm{MN}$ (it is about $0.7 F_{\mathrm{cr}}$ ) and $7.4 \mathrm{MN}$ (it is about $0.9 F_{\mathrm{cr}}$ ). One set of perturbation forces, each of intensity $0.001 F$, is applied at corners $\mathrm{B}$ and $\mathrm{H}$ in the positive $X$-direction to initiate the sway deformation shape. Another set is applied at corners $\mathrm{H}$ and $\mathrm{D}$ in the positive and negative $X$-direction, respectively and at 
corners $\mathrm{F}$ and $\mathrm{B}$ in the positive and negative $\mathrm{Z}$-direction, respectively to initiate the twist deformation shape (Turkalj et al., 2009).

Two different chemical composition carbon steels are used and for the first carbon steel two different temperatures are used. Norton power creep law is adopted with following constants (Beljajev, 1959):

(1) material A - carbon steel $(0.15 \mathrm{C}, 0.50 \mathrm{Mn}, 0.23 \mathrm{Si})$ at $538^{\circ} \mathrm{C}: n=3.05, K=0,12 \cdot 10^{-13}\left[10 \mathrm{~mm}^{2} / \mathrm{N}\right]^{\mathrm{n}} \cdot \mathrm{h}^{-1}$;

(2) material A - carbon steel $(0.15 \mathrm{C}, 0.50 \mathrm{Mn}, 0.23 \mathrm{Si})$ at $649^{\circ} \mathrm{C}: n=2.85, K=0,16 \cdot 10^{-10}\left[10 \mathrm{~mm}^{2} / \mathrm{N}\right]^{\mathrm{n}} \cdot \mathrm{h}^{-1}$

(3) material B - carbon steel $(0.43 \mathrm{C}, 0.68 \mathrm{Mn}, 0.20 \mathrm{Si})$ at $649^{\circ} \mathrm{C}: n=1.7, K=0,12 \cdot 10^{-8}\left[10 \mathrm{~mm}^{2} / \mathrm{N}\right]^{\mathrm{n}} \cdot \mathrm{h}^{-1}$.

Figure 2 shows total translation of corner $\mathrm{B}$ versus creep time for material A at temperatures of $538^{\circ} \mathrm{C}$ and $649^{\circ} \mathrm{C}$ and applied load levels of $0.5 F_{\mathrm{cr}}, 0.7 F_{\mathrm{cr}}$ and $0.9 F_{\mathrm{cr}}$. Deformation shape is sway.

Figure 3 shows total translation of corner $\mathrm{B}$ versus creep time for both, A and B materials at temperature of $649^{\circ} \mathrm{C}$ and applied load levels of $0.5 F_{\mathrm{cr}}, 0.7 F_{\mathrm{cr}}$ and $0.9 F_{\mathrm{cr}}$. Deformation shape is sway.

Figure 4 shows total translation of corner B versus creep time for material A and material B at temperature of $649^{\circ} \mathrm{C}$ and applied load level of $0.5 F_{\text {cr }}$ for different deformation shapes, sway and twist.

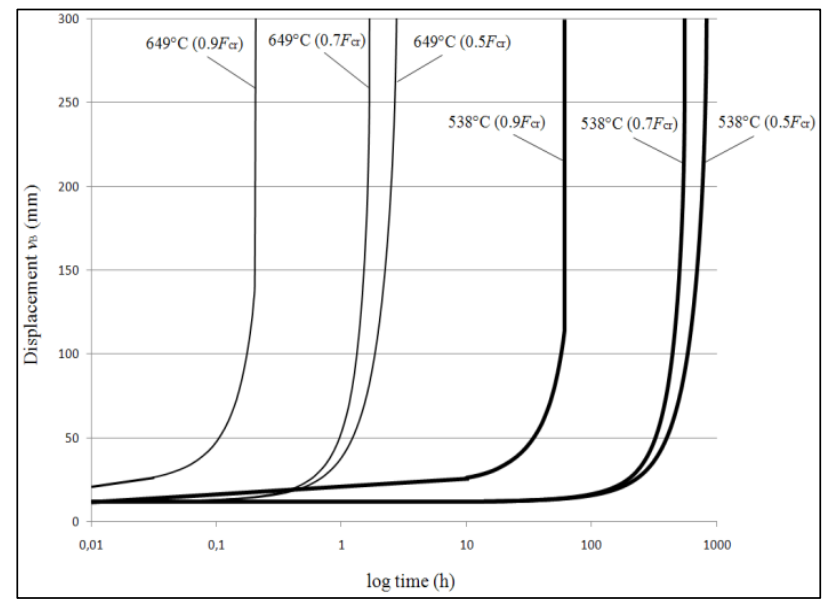

Fig. 2. Buckling curves for material A at $538^{\circ} \mathrm{C}$ and $649^{\circ} \mathrm{C}$

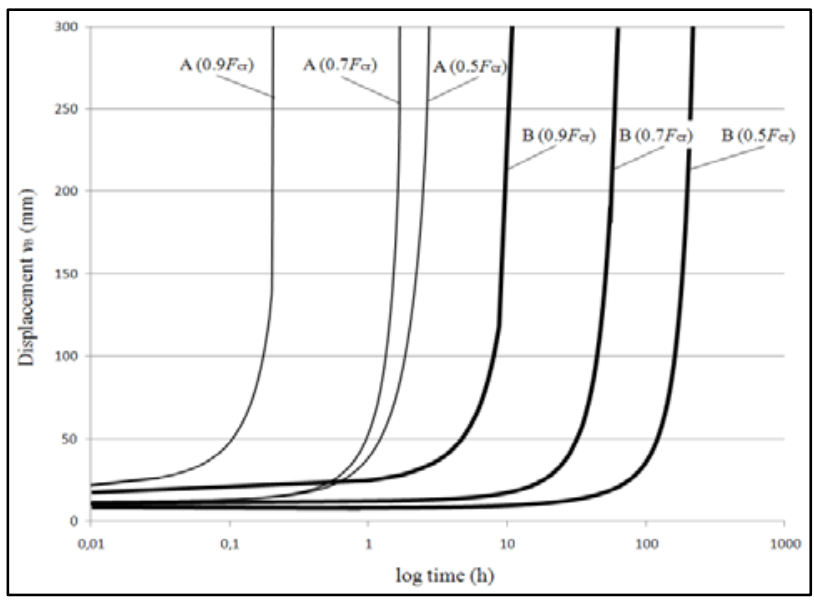

Fig. 3. Buckling curves for material A and B at $649^{\circ} \mathrm{C}$

\begin{tabular}{||r|r|r|r|r||r|r||}
\cline { 2 - 7 } \multicolumn{1}{c|}{} & \multicolumn{4}{c|}{ Material A } & \multicolumn{2}{c||}{ Material B } \\
\cline { 2 - 7 } \multicolumn{1}{c|}{} & $T=538^{\circ} \mathrm{C}$ & \multicolumn{2}{c|}{$T=649^{\circ} \mathrm{C}$} & \multicolumn{2}{|c|}{$T=649^{\circ} \mathrm{C}$} \\
\hline \hline $0.5 F_{\text {cr }}$ & 840 & 3820 & 3 & 11 & 228 & 242 \\
\hline $0.7 F_{\text {cr }}$ & 560 & 616 & 1.5 & 2 & 55 & 63 \\
\hline $0.9 F_{\text {cr }}$ & 60 & 76 & 0.2 & 0.2 & 9 & 11 \\
\hline
\end{tabular}

Tab. 2. Critical buckling times (h)
The critical creep buckling times obtained for different chemical composition carbon steels at different temperatures are listed in Table 2.

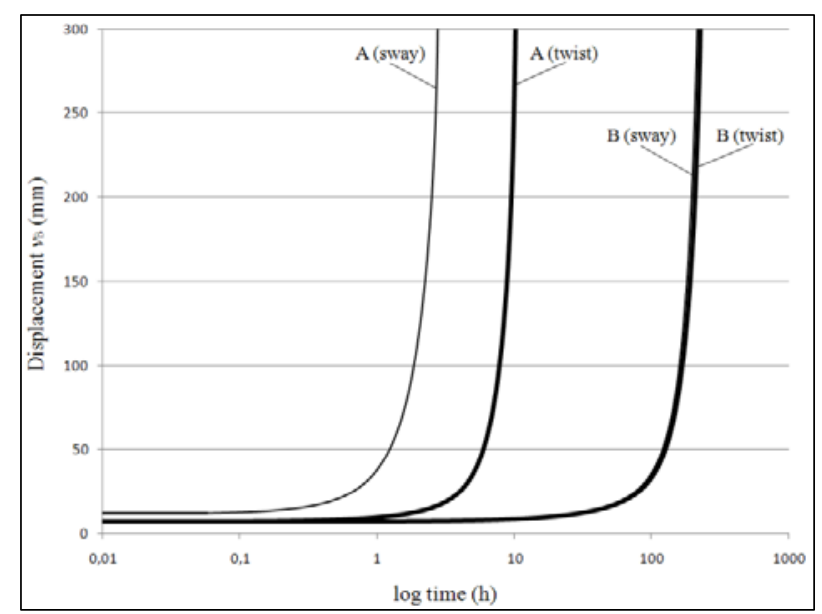

Fig. 4. Buckling curves for sway and twist modes at $0.5 F_{\mathrm{cr}}$

\section{CONCLUSION}

High temperatures which are caused e.g. by fires have significant influence to collapse time of frame structures. Numerical simulation of creep buckling is a fast way of prediction of such phenomena.

From obtained results it can be concluded that material B is more creep resistant than material A. Furthermore, critical buckling time of material A rapidly decreases by temperature growth from $538^{\circ} \mathrm{C}$ to $649^{\circ} \mathrm{C}$. Change of deformation mode has also a great influence to decreasing critical buckling time for material A at lower load levels, while at higher loads this difference is negligible. Mode variation for material B does not change collapse time noticeably.

Even though this analysis includes only creep buckling at constant temperature levels, with slight modifications it is possible to expand it to non-constant temperature environment conditions e.g. in fire.

Future research will also encompass development of a creep buckling computer algorithm based on beam finite elements.

\section{ACKNOWLEDGMENTS}

The research presented in this paper was made possible by financial support of the Ministry of Science, Technology and Sports of the Republic of Croatia, under the project No. 0690691736-1731.

\section{REFERENCES}

Beljajev, N.M. (1959), Soprotivljenje materijalov, Fizmatgiz, Moscow

Lanc, D.; Turkalj, G.; Brnic, J. (2006), Beam model for creep buckling analysis, Proceedings of 5th International Congress of Croatian Society of Mechanics, September, 2123, Trogir/Split, Croatia, ISBN 953-96243-8-X, Matejcek, F. (Ed.), pp. 65-66, Croatian Society of Mechanics, Zagreb

Lanc, D.; Turkalj, G.; Brnic, J. (2008), Finite-element model for creep buckling analysis of beam-type structures, Communications in Numerical Methods in Engineering, Vol. 24, No. 11, pp. 989-1008, ISSN 2040-7939

Nguyen-Thanh, N.; Rabczuk, T.; Nguyen-Xuan, H.; Bordas, S.P.A. (2008), A smoothed finite element method for shell analysis, Comput. Methods Appl. Mech. Engrg., Vol. 198, pp. 165-177, ISSN 0045-7825

Turkalj, G.; Lanc, D.; Brnic, J. (2009), Large displacement analysis of elastic-plastic framed structures under creep regimes, International Journal of Structural Stability and Dynamics, Vol. 9, No. 1, pp. 61-83, ISSN 0219-4554 